\title{
Comunicação
}

[Communication]

\section{Avaliação de uma metodologia profilática contra a mastite clínica em ovelhas da raça Santa Inês.}

\author{
[Evaluation of a prophylactic method against clinical mastitis in Santa Inês ewes]
}

\author{
C.B. Melo ${ }^{1}$, B.M. Almeida ${ }^{2}$, A.A. Oliveira ${ }^{3}$, H.C. Azevedo ${ }^{3}$, L.S.S. Melo ${ }^{1}$, S.S. Mata ${ }^{3}$ \\ ${ }^{1}$ Faculdade de Agronomia e Medicina Veterinária - UnB \\ Caixa Postal 4508 \\ 70910-970 - Brasília, DF \\ ${ }^{2}$ Universidade Federal de Sergipe - São Cristóvão, SE \\ ${ }^{3}$ Embrapa Tabuleiros Costeiros - Aracaju, SE
}

A mastite clínica nas ovelhas Santa Inês é um problema sanitário importante no nordeste brasileiro (Oliveira, 2006). O decréscimo na produção advém de alterações patológicas do tecido glandular do úbere, mas encontram-se também presentes alterações físicas, químicas e microbiológicas do leite. Entretanto, nem sempre as modificações causadas pela mastite ovina podem ser detectadas clinicamente por inspeção ou palpação e a sua evolução pode ocorrer tanto de forma aguda quanto crônica (Calavas et al., 1998). O problema afeta diretamente o desenvolvimento dos cordeiros, gerando animais com baixo peso e provocando o descarte precoce das matrizes por danos irreversíveis ao úbere (Fthenakis e Jones, 1990).

O objetivo deste trabalho foi avaliar uma metodologia de desmame e secagem em ovelhas da raça Santa Inês, como profilaxia para a mastite clínica e compará-la a um método habitual de desmame tradicionalmente desenvolvido pela Embrapa Tabuleiros Costeiros.

O trabalho foi desenvolvido na Estação Pedro Arle (Embrapa Tabuleiros Costeiros), localizada no município de Frei Paulo, Sertão Sergipano, no período de 21 de setembro a 3 de novembro de 2005.

Recebido em 27 de abril de 2007

Aceito em 5 de maio de 2008

Autor para correspondência (corresponding author)

E-mail: cristianomelo@unb.br
Foram selecionadas 62 fêmeas primíparas de partos simples e formaram-se dois grupos de 31 animais. Os grupos permaneceram juntos dentro do manejo habitual na fazenda até 90 dias pósparto, período após o qual foi realizado o desmame. O período experimental teve início naquele momento e todos os animais foram examinados clinicamente no dia do desmame e antes do início do experimento para confirmação de ausência de qualquer alteração no úbere anterior ao experimento, de acordo com Aparício et al. (2002).

No dia do início do experimento, as fêmeas do grupo 1 (G1) tratadas, foram inspecionadas para tamanho do úbere, presença de sinais clínicos de mastite (edema, hiperemia, calor, aumento dos linfonodos retromamários) e submetidas à secagem da glândula mamária por ordenha manual, com prévia higienização das mãos do ordenhador e do úbere com água, sabão, álcool $70 \%$ e secagem com papel toalha. Após a ordenha, as ovelhas foram tratadas com $5 \mathrm{ml}$ de enrofloxacina $250 \mathrm{mg}$ por via intramuscular e permaneceram 48 horas em jejum hídrico e alimentar. As ovelhas do grupo $2(\mathrm{G} 2)$, grupocontrole, foram submetidas à mesma inspeção do úbere, não foram ordenhadas nem receberam antibiótico, isto é, procedeu-se o manejo habitual de secagem. A partir daí, foram realizadas seis avaliações semanais. Naquele momento, 
realizou-se exame de cada úbere, por inspeção e palpação, para identificar o aparecimento de possíveis alterações clínicas típicas de mastite. As informações, anotadas em uma planilha, totalizaram 155 observações para cada grupo e foram observadas por um único examinador.

Para análise dos dados, usaram-se os recursos do programa estatístico SAS (User's..., 2002) utilizando-se o teste do $\chi^{2}$ e o teste exato de Fisher, estabelecendo nível de significância de $1 \%$. Foram calculados intervalos de confiança de 99\% para as estimativas utilizadas (Dean et al., 2002).

Considerando as variáveis úbere hiperêmico e aumento da temperatura do úbere, demonstrou-se maior eficiência nos animais do G1 do que nos do G2 uma vez que no G1 a freqüência desses sinais foi menor, isto é, a resposta foi maior no G1 para as variáveis úbere hiperêmico $\left(\chi^{2}=71,98 ; \mathrm{P}<0,0001\right)$ e aumento da temperatura do úbere $\left(\chi^{2}=68,00\right.$; $\mathrm{P}<0,0001)$. Observaram-se 13 casos $(8,4 \%)$ no $\mathrm{G} 1 \mathrm{e}$ $64(41,3 \%)$ no G2 para ambas as observações, sendo diferentes $\left(\chi^{2}=44,94 ; \mathrm{P}<0,0001\right)$ a partir da terceira semana experimental.

Quanto à variável aumento dos linfonodos supramamários também houve diferença entre grupos $\left(\chi^{2}=35,94 ; \mathrm{P}<0,0001\right)$ a partir da terceira semana.

Em relação à variável presença de leite residual, a freqüência foi menor nos animais do G1, em 47 observações $(24,3 \%)$ que nos do G2, 115 observações $(74,2 \%)$. A diferença foi significativa $\left(\chi^{2}=59,78 ; \mathrm{P}<0,0001\right)$, isto é, o leite residual permaneceu em média, até a sexta semana no G2 e ao redor da quarta semana experimental no G1.

O tratamento possibilitou o desaparecimento mais rápido dos sinais de edema $(\mathrm{P}<0,0001)$. Na última semana, quando já não mais havia leite residual, o endurecimento do úbere (14/62) e o aumento dos linfonodos (12/62) ainda estavam presentes em ambos os grupos $(\mathrm{P}<0,0001) . \mathrm{Na}$ Inglaterra, a ocorrência de anormalidades mamárias durante o período seco foi de 5,5\% (Jones, 2000).

As ovelhas Santa Inês, diferentemente de outras raças especializadas para corte, apresentam longo período de lactação, fato relevante na ocorrência da mastite, pois enquanto o úbere permanecer com leite residual, distendido, haverá favorecimento da penetração e da mobilização das bactérias no tecido glandular, causando alterações mais extensas, além do que a presença de leite residual é excelente meio de cultura (Jones e Lanyon, 1990), o que comprova a limitação do G2. Ainda que limitado, o método tradicional de secagem resultou em um certo controle da mastite, mais demorado que o método proposto.

A utilização de antibióticos torna-se necessária no momento do desmame e da secagem, por conta da evolução de uma provável mastite para uma septicemia, causa comum de morte de ovelhas Santa Inês primíparas. A ausência de antibióticos intramamários para ovelhas forçou a opção pelo antibiótico intramuscular de amplo espectro, pois o procedimento de tratar deve ser imediato e concomitante ao desmame. Assim, o principal objetivo do antibiótico foi prevenir a septicemia por conta de uma mastite aguda. Da mesma forma, a secagem (esgota) da glândula mamária no momento do desmame favoreceu as ovelhas do G1.

O tratamento proposto foi favorável ao controle da mastite clínica nas ovelhas Santa Inês por reduzir de forma significativa a ocorrência dos sinais clínicos. Além disso, essas observações mostraram-se relevantes diante dos relatos de Buswell e Yoman (1976) e Calavas et al. (1998), que consideraram a terceira e quarta semana pós desmame o período crítico para a ocorrência de mastite clínica em ovelhas.

Palavras-chave: ovino, Santa Inês, lactação, secagem, mastite

\section{ABSTRACT}

Mastitis is an important problem for the Santa Inês ewes and is a disease strongly related to the management carried out in the herd. A comparative study was carried out between the proposed method based on drying (treatment) and the traditional method (control). Sixty-two Santa Inês ewes raised in a semi-extensive system were divided in two groups of 31 ewes each: treatment group (G1) and control 
group (G2). The animals were monitored each week searching for clinical sings of mastitis. In $8.4 \%$ of G1 and $41.3 \%$ of G2 animals, the udder was warm and hyperemic. The presence of residual milk was lower in G1 (24.3\%) compared to those of G2 (74.2\%). The proposed treatment for the control of ovine mastitis significantly reduced the frequency of the clinical signs of the disease.

Keywords: sheep, Santa Inês, lactation, drying off, mastitis

\section{AGRADECIMENTOS}

À Fundação de Amparo à Pesquisa do Estado de Sergipe (FAP-SE) por ter financiado o trabalho (Editais FAP-SE/FUNTEC/MCT/CNPq n. 03/2003 e FAP-SE/FUNTEC/MCT/CNPq n. 01/2004). Também somos gratos a Evandro Neves Muniz, Sílvio Aragão Almeida, Gabriel Oliveira Martins e José Almeida Fontes pelo auxílio técnico.

\section{REFERÊNCIAS BIBLIOGRÁFICAS}

APARÍCIO, N., PANIAGUA, J.P., BASEALGA, R. et al. Mamary glands. Introducing a program for the control of mastitis in goats and sheep. Circulares Exopol. 2002. Disponível em http://www.goatconnection.com/articles/publish/ article_121.shtml_Acessado em: 2 jun. 2006.

BUSWELL, J.F.; YEOMAN, G.H. Mastitis in dry ewes. Vet. Rec., v.99, p.221-222, 1976.

CALAVAS, D.; BUGNARD, F.; DUCROT, C. et al. Classification of the clinical types of udder disease affecting nursing ewes. Small Rum. Res., v.29, p.21-31p. 1998.
DEAN, A.G.; DEAN, J.A.; BURTON, A.H. EpiInfo 6, Version 1.2: a word processing, data base, and statistic program for epidemiology on microcomputers. Atlanta: Centers for Disease Control, 2002.

FTHENAKIS, G.C.; JONES, J.E.T. The effect of experimentally induced subclinical mastitis on milk yield of ewes and on the growth of lambs. Br. Vet. J., v.146, p.43-49, 1990.

JONES, J.E.T.; LANYON, M. An investigation of the incidence and causes of mastitis in ewes in lowland flocks. The Sheep Farmer, v.53, p.9-10, 1990.

JONES, J.E.T. Mastitis in sheep. In: OWEN, J.B.; AXFORD, R.F.E. (Eds). Breeding for disease resistance in farm animals. Wallingford: CAB International, 2000. p.412-413;

OLIVEIRA, V.L.M. Aspectos do leite e mastite em ovinos da raça Santa Inês em Sergipe. 2006. 70f. Dissertação (Mestrado) - Universidade Federal de Sergipe, São Cristóvão.

USER'S guide: statistical analysis system. Release 8.01. Cary, NC: SAS Institute, 2002. 